\title{
In vitro cultivation of Trypanoplasma borreli (Protozoa: Kinetoplastida), a parasite from the blood of common carp Cyprinus carpio
}

\author{
Dieter Steinhagen ${ }^{1, *}$, Wencke Hedderich ${ }^{1}$, Andreas Skouras ${ }^{1}$, Jörn P. Scharsack ${ }^{1}$, \\ Joachim Schuberth ${ }^{2}$, Wolfgang Leibold ${ }^{2}$, Wolfgang Körting ${ }^{1}$
}

${ }^{1}$ Fish Disease Research Unit, and ${ }^{2}$ Immunology Unit, School of Veterinary Medicine, PO Box 711180, 30545 Hannover, Germany

\begin{abstract}
An in vitro culture system was developed for Trypanoplasma borreli, a pathogenic flagellate from the blood of European cyprinids. Trypanoplasms multiplied rapidly in a mixture of Hanks' balanced salt solution (HBSS, 45\%), L15 (22.5\%), Earle's minimum essential medium (MEM, $22.5 \%$ ) and $10 \%$ distilled water, which was supplemented with 5 to $10 \%$ heat-inactivated pooled carp serum. In medium supplemented with fetal bovine serum, multiplication of $T$. borreli seemed to be inhibited. Cultures initiated with less than 100000 T. borreli per ml culture medium did not survive, and a substantial multiplication of trypanoplasms was found at inocula beginning with 630000 flagellates $\mathrm{ml}^{-1}$. Trypanoplasms multiplied at 15,20 and $25^{\circ} \mathrm{C}$. In cultures incubated at $4^{\circ} \mathrm{C}$ the trypanoplasms remained viable but the number of flagellates did not increase. Trypanoplasms from in vitro cultures retained their infectivity for carp for at least $90 \mathrm{~d}$ ( 5 passages). The trypanoplasms survived in culture over a period of up to 5 mo (10 passages). The established culture system allows the propagation of high numbers of fish-infective trypanoplasms, which are required to study parasitehost relationships in carp
\end{abstract}

KEY WORDS: Trypanoplasma borreli $\cdot$ Haemoflagellate $\cdot$ In vitro culture

\section{INTRODUCTION}

Trypanoplasma borreli Laveran \& Mesnil, 1901 is a pathogenic blood flagellate from cyprinid fishes in Europe. It is transmitted by the blood-sucking leeches Piscicola geometra and Hemiclepsis marginata and causes 'sleeping sickness' of common carp Cyprinus carpio and tench Tinca tinca (Lom \& Dykova 1992, Woo \& Poynton 1995). For experimentation, the parasite was successfully transmitted by the injection of blood from infected fish into muscle or body cavity of recipient fish (Jones at al. 1993), and a cloned strain was established (Steinhagen et al. 1989). Infections of carp with $T$. borreli can easily be induced and monitored and therefore are good models for the study of interactions of the parasite with the host immune system (Jones et al. 1995, Wiegertjes et al. 1995) and mechanisms of pathogenesis (Lom \& Dykova 1992,

•E-mail: dstein@fisch.tiho-hannover.de
Bunnajirakul et al. 2000). For these purposes, an adequate supply of bloodstream forms of $T$, borreli is a prerequisite.

To produce a constant supply of parasite material for such experiments, in vitro cultures of trypanoplasms are needed. Successful culture systems were established for Trypanoplasma (Syn. Cryptobia) salmositica from the blood of North American salmonids and $T$ bullocki from North American flounders. These flagellates are closely related to $T$. borreli and were cultivated in media based on Hanks' salt solution ( $T$. salmositica) or minimum essential medium ( $T$, bullocki, $T$. salmositica) and supplemented with heat-inactivated bovine serum (Woo \& Poynton 1995). In these media, the trypanoplasms multiplied rapidly and were still able to infect fish after a prolonged period of cultivation (Woo \& Li 1990). In vitro cultures of $T$. borreli were performed in diphasic blood agar medium (SNB9), supplemented with vitamins and antibiotics (Hajdu \& Matskasi 1984, Nohynkova 1984, Peckova \& Lom 1990). In these cultures, however, $T$. borreli lost its 
infectivity for fish after 10 to $14 \mathrm{~d}$ of primary culture (Peckova \& Lom 1990) or after 6 subcultures (Nohynkova 1984).

The present study was undertaken to establish an in vitro cultivation procedure for Trypanoplasma borreli that allows easy propagation of the parasite, isolation of high numbers of trypanoplasms without contaminating blood and serum components, and maintainance of the parasite's infectivity for carp and goldfish.

\section{MATERIALS AND METHODS}

Fish. Carp from a single crossing (E20 $\times$ R8, Wageningen Agricultural University, The Netherlands, known to be highiy suscepiible to Trypanopiasma borreli; Bunnajirakul et al. 2000) were used throughout the study. The female (E20) originated from an outbred female which was gynogenetically reproduced. This isogenetic female was crossed with an outbred male of Hungarian origin (Wiegertjes et al. 1995). The carp were reproduced and raised under parasite-free conditions in filtered recirculating tap water at $20 \pm 2^{\circ} \mathrm{C}$ and fed daily with commercial carp chow (Alma, Kempten, Germany). In experiments the carp were used at an age of $11 \mathrm{mo}$ and a body weight of 150 to $200 \mathrm{~g}$.

Flagellates. The strain of Trypanoplasma borreli used in this study was isolated from a naturally infected common carp, cloned and characterized as described earlier (Steinhagen et al. 1989). The parasite was maintained by syringe passage through highly susceptible carp (strain E20 $\times$ R8) by intramuscular inoculation of $5000 \mathrm{~T}$. borreli.

Isolation and purification of Trypanoplasma borreli from the blood of infected carp. Infected carp were anaesthetized by immersion in a solution of $0.15 \%$ aminobenzoic acid ethylester methansulphonate (Sigma, St. Louis, MO, USA). They were then bled from the caudal vein into syringes prefilled with $1 \mathrm{ml}$ of heparinized [50 IU sodium heparin $\mathrm{ml}^{-1}$ ] RPMI 1640 medium, drawing off $4 \mathrm{ml}$ of blood. The trypanoplasms were purified from the blood cells by the method of Bienek \& Belosevic (1997). Briefly, the diluted parasitecontaining blood was centrifuged for $5 \mathrm{~min}$ at $9 \times g$ and subsequently for $10 \mathrm{~min}$ at $400 \times \mathrm{g}$. Then the buffy coat and the supernatant were removed with minimal disturbance of the erythrocyte pellet and transferred to a second centrifugation tube. Here, the parasites from the buffy coat were suspended in washing medium (RPMI 1640 supplemented with $10 \%$ of double distilled water, $10 \mathrm{IU}$ sodium heparin $\mathrm{ml}^{-1}$ ) and spun again $\left(10 \mathrm{~min}, 400 \times g, 4^{\circ} \mathrm{C}\right)$. After centrifugation half of the washing medium was removed and the parasites were separated from the erythrocyte pellet by carefully agitating the tube in circles. By this procedure the flagellates were resuspended in the washing medium while most of the erythrocytes remained attached to the bottom of the tube. The supernatant with the parasites was transferred to a second centrifugation tube and spun again once at $400 \times g$. The resuspension and centrifugation steps were repeated once more to remove most of the erythrocytes. Following the last centrifugation, the vial was tilted to an angle of approx. $20^{\circ}$ for 5 to $10 \mathrm{~min}$. The trypanoplasms then separated from the pelleted cells and were found on the wall of the vial. The flagellates were pipetted off, resuspended and counted in a haematocytometer.

Culture media. For cultivation experiments, the following media were used: RPMI 1640 (Biochrom, Berlin, Germany, Cat. No. T 21-10), Leibovitz L 15 (L15; Blochrom, Cat. No. 1315), Hanks' buffered salt solution (HBSS, Biochrom, Cat. No. 182-01), Earle's modified minimum essential medium (MEM, Biochrom, Cat. No. F 03515), and a mixture of HBSS $(45.0 \%)$, L15 $(22.5 \%)$, MEM $(22.5 \%)$ and doubledistilled water $(10 \%)$ (MLH medium; Wang \& Belosevic 1994). All media were supplemented with $2 \mathrm{mmol}$ $\mathrm{I}^{-1}$ L-glutamin (Biochrom Cat No. K 0280), 100 IU penicillin $\mathrm{ml}^{-1}$ and $100 \mu \mathrm{g}$ streptomycin $\mathrm{ml}^{-1}$ (Biochrom, Cat No. A 2212). To meet the osmolarity of carp blood, the

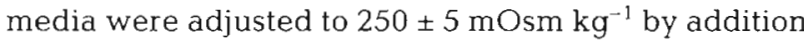
of $10 \%(\mathrm{v} / \mathrm{v})$ of double-distilled water. The cultivation media contained either $10 \%$ fetal bovine serum (FBS), $1 \%, 3 \%, 5 \%$ or $10 \%$ carp serum (CS), or $1 \%, 3 \%, 5 \%$ or $10 \%$ carp plasma (CP). Fish serum was obtained by anaesthetizing and bleeding parasite-free carp as described above. The blood was allowed to clot, centrifuged $(2000 \times g)$ and the supernatant serum collected. The sera collected from 5 to 7 fish were pooled heat-inactivated $\left(30 \mathrm{~min}\right.$ at $\left.56^{\circ} \mathrm{C}\right)$, filter-sterilized (0.45 $\mu \mathrm{m}$, Schleicher \& Schuell, Dassel, Germany) and stored frozen until use.

In some experiments, the culture media were supplemented with carp erythrocyte lysates. The erythrocytes were obtained by bleeding parasite-free carp into syringes prefilled with heparinized RPMI 1640 as described above. The erythrocytes were pelleted by centrifugation, washed twice in washing medium as described above, resuspended in culture medium at a density of $1 \times 10^{7}$ cells $\mathrm{ml}^{-1}$ and lysed by 3 circles of freezing at $-80^{\circ} \mathrm{C}$ and thawing. Finally, the cell suspension was centrifuged at $2000 \times \mathrm{g}$. The supernatant was harvested, filter-sterilized and stored frozen $\left(-80^{\circ} \mathrm{C}\right)$ until use.

Cultivation of Trypanoplasma borreli. Purified trypanoplasms were inoculated into microtiter plates, Leighton tubes or $25 \mathrm{~cm}^{2}$ flasks at varying densities and incubated at 15,20 , or $25^{\circ} \mathrm{C}$ in air. The medium was changed at intervals of 3 to $5 \mathrm{~d}$ and the number of trypanoplasms was determined. This was done by re- 
suspending the trypanoplasms in the medium, removing a small amount and enumerating the flagellates in a haemocytometer. In addition, the number of flagellates was determined by the standard cell dilution assay (Pechold \& Kabelitz 1998) by means of a flow cytometer. All culture experiments were done in duplicate.

Flow cytometric analysis of Trypanoplasma borreli. For quantitative and qualitative flow cytometric analysis, samples were resuspended thoroughly and transferred to polystyrene tubes. Propidium iodide $(2 \mu \mathrm{g}$ $\left.\mathrm{ml}^{-1}\right)$ and a suspension with a defined number $\left(4 \times 10^{4}\right)$ of standard cells was added. Standard cells were paraformaldehyde-fixed bovine blood mononuclear cells which were labelled with a murine monoclonal antibody directed against bovine MHC class I molecules (mAb Bo 1; Schuberth et al. 1992) and then with FITC conjugated goat anti-mouse immunoglobulins (Dia nova, Hamburg, Germany). Forward light scatter (FSC, corresponding to cell size), side light scatter (SSC, corresponding to cell complexity), and fluorescence characteristics were recorded for 10000 events of each sample by means of a FACScan ${ }^{\circledR}$ flow cytometer (Becton Dickinson, Heidelberg, Germany) and evaluated using the WinMDI 2.7 software package (Trotter 1998). Numbers of viable trypanoplasms were calculated according to the formula: Events [propidium iodide-negative trypanoplasms] $\times$ Number[standard cells]/Events [standard cells].

Infectivity of cultured Trypanoplasma borreli for carp. Trypanoplasms from a strain cultivated in MLH medium supplemented with $5 \%$ or $10 \%$ carp serum at $20^{\circ} \mathrm{C}$ were inoculated into highly susceptible carp after 60 and $90 \mathrm{~d}$ of cultivation. The carp were kept in aquaria with recirculated and filtered tap water at $20^{\circ} \mathrm{C}$. At weekly intervals, blood samples were taken and examined for the presence of $T$. borreli. The numbers of parasites were determined using a haemocytometer.
Statistics. Two-way analysis of variance and Dunn's least significant differences test were used to compare differences between treatment groups at different dates. Probability values of less than $5 \%$ were considered to be significant.

\section{RESULTS}

\section{Isolation of Trypanoplasma borreli and flow cytometric analysis of $T$. borreli suspensions}

Using the isolation method applied here, highly purified populations of Trypanoplasma borelli were obtained. After flow cytometric analysis, $T$. borreli displayed lower FSC and higher SSC characteristics compared to carp peripheral blood lymphocytes and thus could be recognized and gated in FSC versus SSC dotplots (Fig. 1). Based on these characteristic morphological flow cytometric parameters, the suspensions of isolated $T$. borreli contained $\geq 95 \%$ of viable, propidium iodide-negative trypanoplasms

The quantitation of trypanoplasms cultivated in vitro under various conditions was performed by a flow cytometric procedure (standard cell dilution assay, see 'Materials and methods'). This method was validated by parallel counting of 84 samples with a haemocytometer. The numbers of Trypanoplasma borreli calculated by both methods were comparable and did not differ significantly $(p>0.1)$.

\section{Survival and growth of Trypanoplasma borreli in vitro}

The viability of trypanoplasms incubated in RPMI 1640 culture medium supplemented with $3 \%$ carp serum decreased rapidly, and after $10 \mathrm{~d}$ the culture harboured only few actively moving flagellates. When
Fig. 1. (a) Forward/side scatter (FSC/SSC) diagram of Trypanoplasma borreli isolated from the circulating blood of laboratoryinfected carp. (b) Scatter diagram of blood leukocytes from a carp infected with $T$. borreli in the laboratory. Propidium iodide-positive and deteriorating cells with low FSC scatter characteristics were excluded from the analysis. Trypanoplasms exhibited a characteristic FSC/SSC pattern (R1) and could be distinguished from peripheral blood cells (R2)
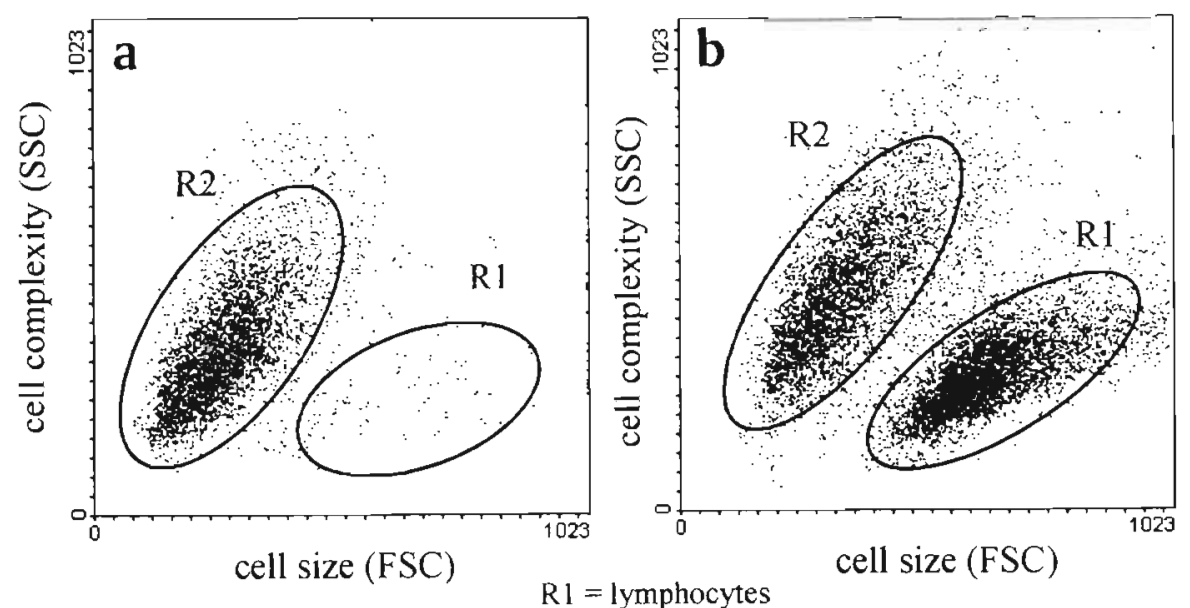

$\mathrm{R} 1$ = lymphocytes

$\mathrm{R} 2=\mathrm{T}$. borreli 


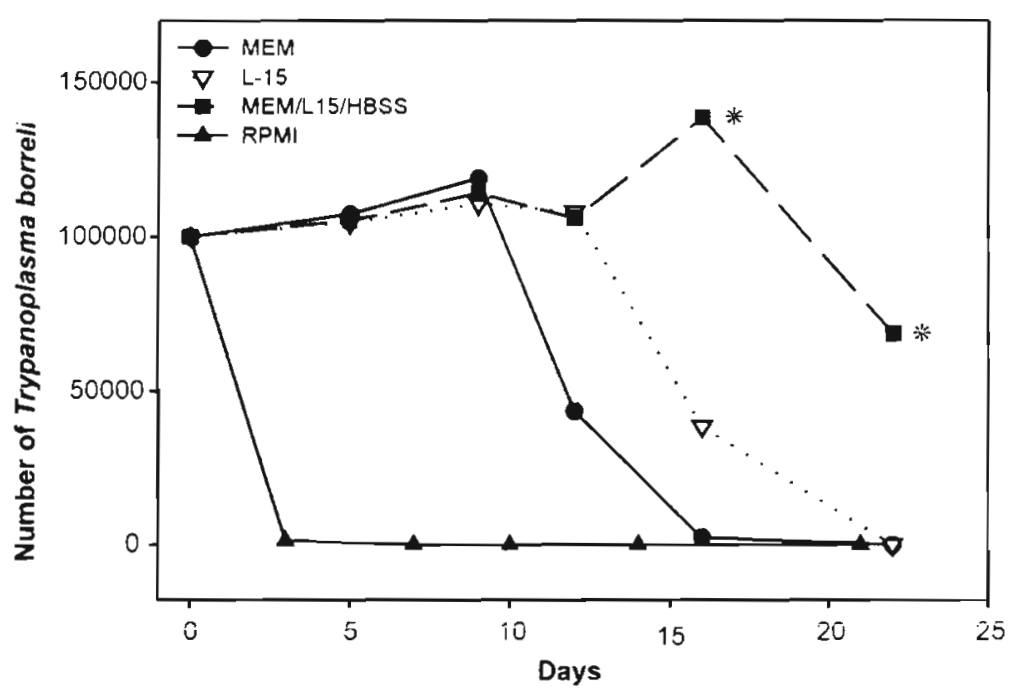

Fig. 2. Cultivation of Trypanoplasma borreli in different culture media. Values represent the average numbers of viable $T$. borreli from duplicate cultures after incubation of 100000 flagellates in $150 \mu$ l of RPMI $1640, \mathrm{~L} 15$, MEM or a mixture of MEM, L15 and HBSS (MLH medium). The media were supplemented with $10 \%$ pooled carp serum. The cultures were incubated at $15^{\circ} \mathrm{C}$. * Statistically significant $(p<0.05)$ more $T$ borrell in cul-

tures with MEM/L15/HBSS compared to other culture media tested lates a high serum supplementation was required. Even though trypanoplasms multiplied in the presence of $1 \%$ or $3 \%$ of CS, flagellate numbers in cultures with $5 \%$ or $10 \%$ serum were significantly higher after $30 \mathrm{~d}$ of cultivation (Fig. 4).

The number of Trypanoplasma borreli initially inoculated into MLH medium with $5 \%$ CS significantly influenced the proliferation of trypanoplasms. When duplicate cultures were started with less than $1 \times 10^{5}$ $T$. borreli $\mathrm{ml}^{-1}$, no proliferation, or even a decrease of flagellate numbers, was observed (Table 1). Maximum growth rates were observed at densities between $2 \times$ $10^{\circ}$ and $10 \times 10^{\text {s}}$ trypanoplasms $\mathrm{ml}^{-1}$ culture medium (Table 1). In cultures initiated with $T$. borreli at a density of $30 \times 10^{5}$ or $60 \times 10^{5}$ flagellates $\mathrm{ml}^{-1}$, a significantly slower proliferation of trypanoplasms occurred (Table 1).

The influence of temperature on the proliferation of Trypanoplasma borreli was examined by incubating trypanoplasms at $4,15,20$, or $25^{\circ} \mathrm{C}$. In cultures maintained at 15,20 or $25^{\circ} \mathrm{C}$, a rapid increase of flagel- incubated in L15, MEM or MEM/L15/HBSS (MLH medium; always with a 3\% carp serum supplementation), no loss in viability was observed for a period of $10 \mathrm{~d}$. Trypanoplasms cultivated in MLH medium survived significantly longer than in the other culture media tested (Fig, 2).

In different experiments the effect of serum supplementation of the MLH medium on the in vitro growth of Trypanoplasma borreli was determined. Medium supplemented with $10 \%(\mathrm{v} / \mathrm{v}) \mathrm{CS}$ supported a rapid proliferation of $T$. borreli. Over a period of $25 \mathrm{~d}$, the number of $T$. borreli increased from $2 \times$ $10^{6}$ up to more than $70 \times 10^{6}$ trypanoplasms (Fig. 3). In cultures supplemented with $10 \%$ (v/v) FBS, the trypanoplasms did not show signs of loss of viability, but flagellate numbers did not increase. The addition of a mixture of $10 \% \mathrm{FBS}$ and $1 \% \mathrm{CS}$ resulted in a slight increase of numbers which was significantly less than that seen in cultures supplemented with $10 \%$ CS (Fig. 3).

In a second set of experiments, Trypanoplasma borreli were incubated with $1 \%, 3 \%$, $5 \%$ or $10 \%$ of CS or CP. Trypanoplasms cultivated in the presence of CS proliferated significantly faster than those incubated in media supplemented with the same amount of CP (Fig. 4). For a rapid growth of flagel-

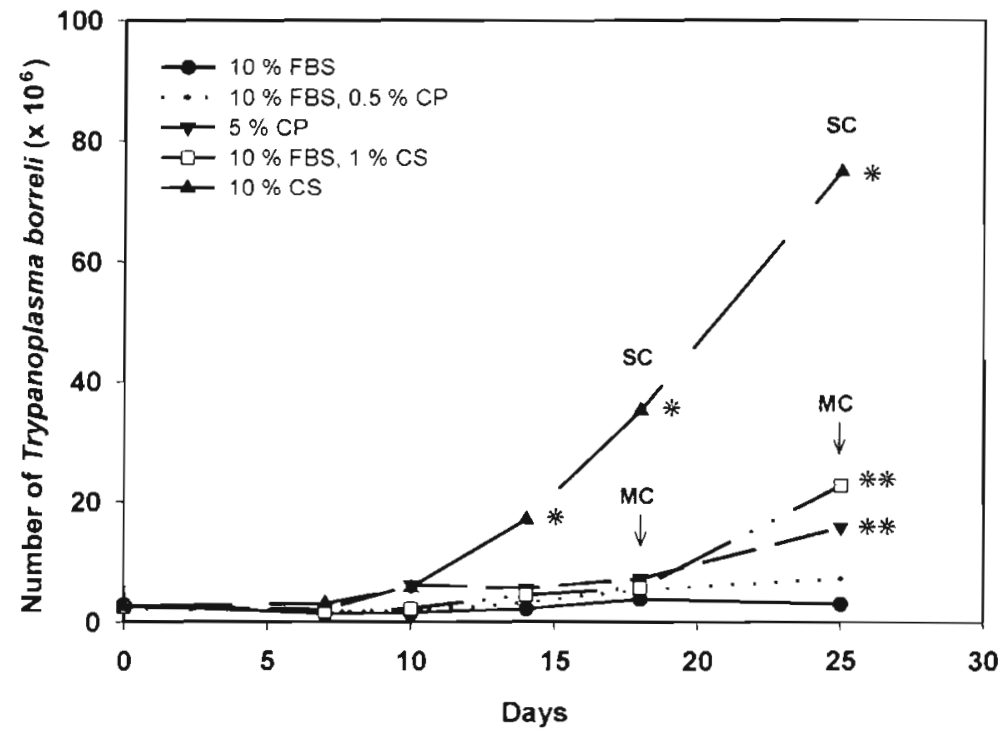

Fig. 3. Growth of Trypanoplasma borreli in culture media supplemented with fetal bovine serum. In these cultures, $1 \times 10^{6} T$ borreli were incubated in MLH medium supplemented with fetal bovine serum (FBS), pooled carp plasma (CP), heat-inactivated pooled carp serum (CS) and mixtures of FBS, CP, and CS. The cultures were incubated at $15^{\circ} \mathrm{C}$. Values represent average numbers of $T$. borreli from duplicate cultures. MC: partial change of culture medium; SC: subcultures. *Statistically significant differences $(p<0.001)$ between $10 \%$ CS and other supplements. * Statistically significant differences $(p<0.01)$ between $[10 \%$ FBS, $1 \% \mathrm{CS}]$ and $[5 \% \mathrm{CP}],[10 \% \mathrm{FBS}, 0.5 \% \mathrm{CP}]$ or $[10 \% \mathrm{FBS}]_{i}$ and between $[5 \% \mathrm{CP}]$ and $[10 \% \mathrm{FBS}, 0.5 \% \mathrm{CP}]$ or $[10 \% \mathrm{FBS}]$ 
late numbers was observed (Fig. 5). Compared to cultures kept at $15^{\circ} \mathrm{C}$, this increase was significantly faster at 20 and $25^{\circ} \mathrm{C}$. At $4^{\circ} \mathrm{C} \mathrm{T}$. borreli survived and proliferated at extremely low rates (Fig, 5). Trypanoplasms which were stored at $4^{\circ} \mathrm{C}$ for $4 \mathrm{wk}$ and then transferred to 15,20 or $25^{\circ} \mathrm{C}$ showed similar growth rates to trypanoplasms which were inoculated into culture medium immediately after isolation from carp blood (data not shown)

We were able to maintain Trypanoplasma borreli in culture in MLH medium supplemented with $5 \% \mathrm{CS}$ at $20^{\circ} \mathrm{C}$ for up to 10 passages over a period of $5 \mathrm{mo}$.

\section{Infectivity of Trypanoplasma borreli from in vitro cultures to common carp}

All carp injected with trypanoplasms from in vitro cultures in MLH medium supplemented with CS acquired a Trypanoplasma borreli infection. At Day 23 post-infection, carp injected with flagellates which had been cultivated in this medium at $20^{\circ} \mathrm{C}$ for $90 \mathrm{~d}$ had a parasitaemia of 1.7 to $7.2 \times 10^{7}$ T. borreli $\mathrm{ml}^{-1}$ blood.

\section{DISCUSSION}

We were able to isolate trypanoplasms from the blood of infected carp in high numbers and with little contamination by fish blood cells. This was confirmed by microscopic and flow cytometric analysis of flagellate suspensions. With the flow cytometric analysis of Trypanoplasma borreli sus-

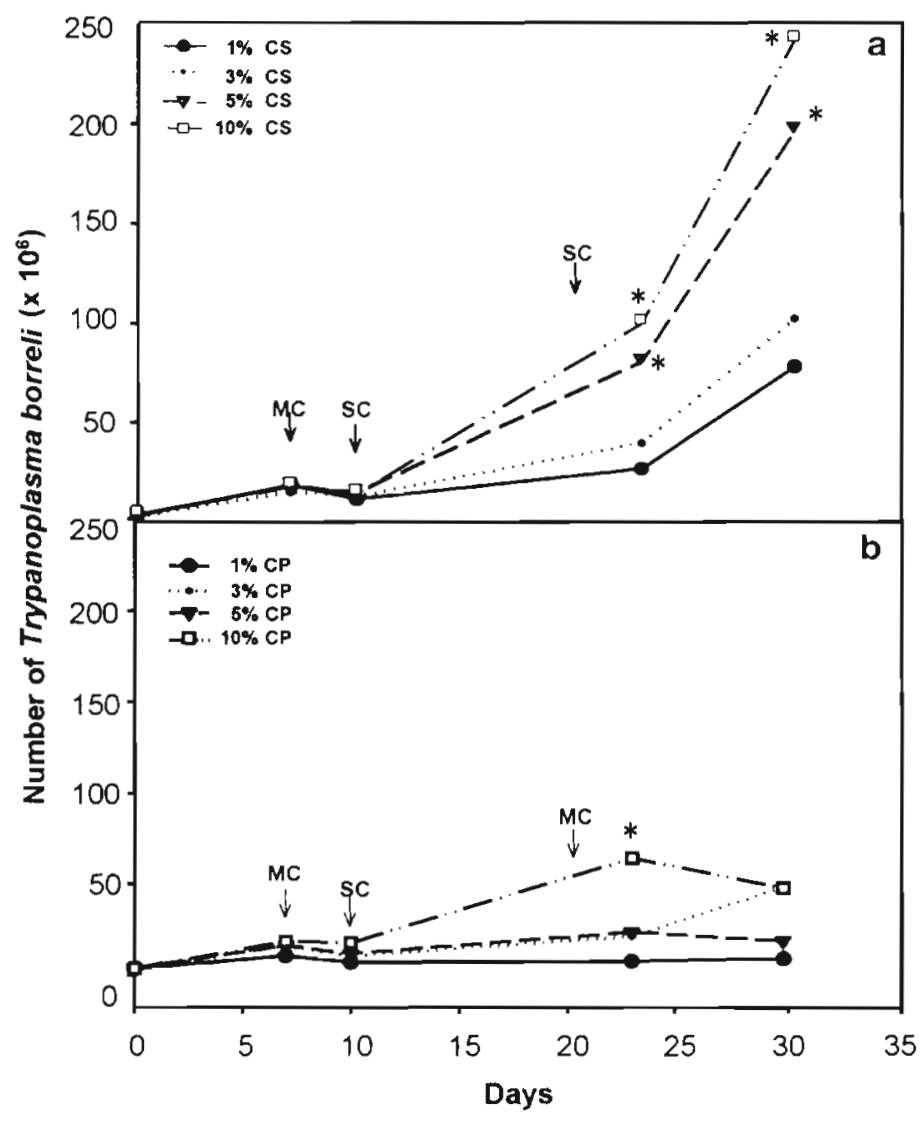

Fig. 4. Propagation of Trypanoplasma borreli in culture medium containing different amounts of (a) carp serum or (b) plasma. The trypanoplasms were incubated at $20^{\circ} \mathrm{C}$ at a density of $1 \times 10^{6} \mathrm{fla}$ gellates $\mathrm{ml}^{-1}$. The media were supplemented with lysates of $1 \times 10^{5}$ carp erythrocytes $\mathrm{ml}^{-1}$ Values are average numbers of $T$ borreli from duplicate cultures. CS: heat-inactivated pooled carp serum, CP: pooled carp plasma. MC: partial change of culture medium; SC: subculture.*Statistically significant differences $(p<0.01)$ between $5 \% \mathrm{CS}$ and $1 \% \mathrm{CS}$ or $3 \% \mathrm{CS}$; and between $10 \% \mathrm{CS}$ and $1 \% \operatorname{CS}$ or $2 \% \mathrm{CS}$

Table 1. Vitality of Trypanoplasma borreli cultured in vitro is influenced by the numbers of parasites initially inoculated. The trypanoplasms were incubated in MLH medium supplemented with $5 \% \mathrm{CS}$ and kept at $20^{\circ} \mathrm{C}$ in air. Values are multiplicity of vital $T$. borreli, represented by the fractions: [Number of vital $T$. borreli measured in the cultures]/[Number initially inoculated]. Average values from duplicate cultures; -: not determined

\begin{tabular}{|lcccc|}
\hline $\begin{array}{l}\text { Inoculated } \\
\text { T. borreli }\left[\times 10^{5}\right]\end{array}$ & 6 & 11 & 13 & 19 \\
\hline 0.1 & 0.5 & 0 & - & - \\
0.2 & 0.7 & 0 & - & - \\
1.0 & 1.2 & - & 1.0 & - \\
2.0 & 3.3 & 6.6 & 8.8 & - \\
10.0 & 5.0 & 15.1 & - & 32.5 \\
30.0 & 1.9 & 3.4 & - & 6.8 \\
60.0 & 1.7 & 2.2 & - & 4.5 \\
\hline
\end{tabular}

pensions we were able (1) to discriminate trypanoplasms from blood cells and (2) by applying the standard cell dilution assay (Pechold \& Kabelitz 1998) to determine absolute numbers of flagellates per sample with high accuracy.

In the culture system for Trypanoplasma borreli we describe here a fish-infective strain of the parasite was propagated and cultivated for a long period. Several reports on the cultivation of $T$. borreli have been published previously (cf. review by Lom \& Dykova 1992). The parasites can be grown in the biphasic medium SNB 9 which consists of a rabbit or human blood-agar solid phase and an overlay with vitamins and neopeptone (Opperdoes et al. 1988, Peckova \& Lom 1990). It also multiplies in a monophasic LIT-medium, which consists of a suspension of liver infusion, tryptose and electrolytes (Wiemer et al. 1995). In these media, the 


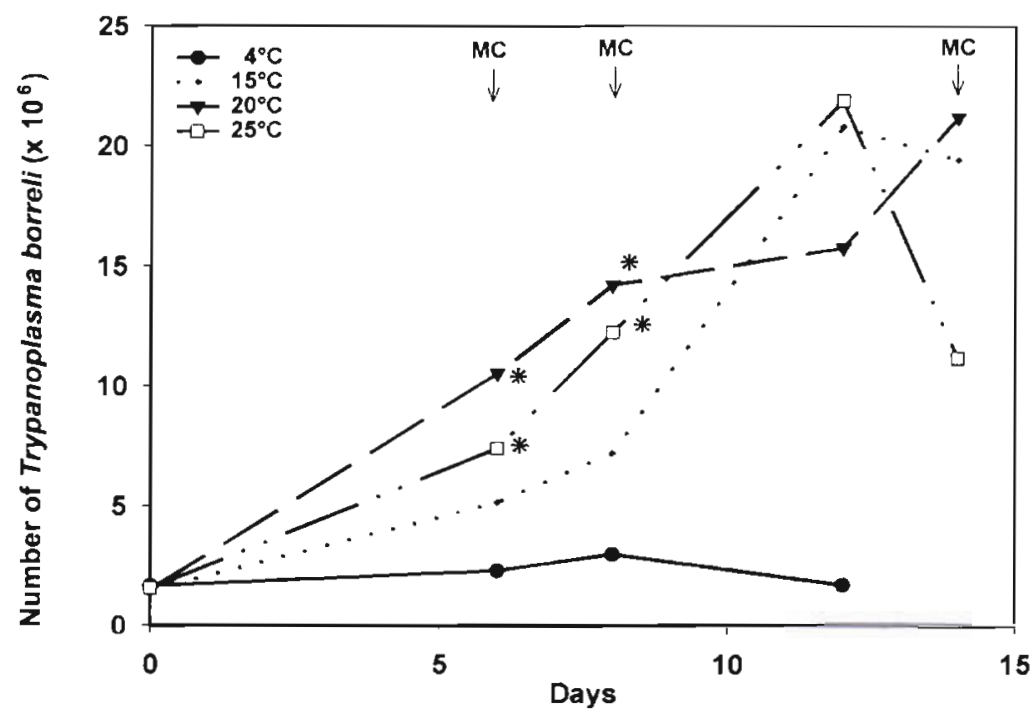

Fig. 5. Cultivation of Trypanoplasma borreli at different incubation temperatures. The flagellates were incubated in MLH-medium supplemented with $10 \% \mathrm{CS}$ at a density of $1 \times 10^{6}$ trypanoplasms $\mathrm{ml}^{-1}$ and incubated at 4,15 , 20 , and $25^{\circ} \mathrm{C}$. The culture medium was partially changed at Days 6,9 , and 14 and is indicated by MC. Values are average numbers of $T$. borreli from duplicate cultures. * Statistically significant differences $(\mathrm{p}<0.01)$ between $15^{\circ} \mathrm{C}$ and 20 or $25^{\circ} \mathrm{C}$. The numbers of $T$. borreli in $4^{\circ} \mathrm{C}$ cultures were always significantly $(p<0.001)$ lower than in cultures at 15,20 or $25^{\circ} \mathrm{C}$

(Jones 1993, Koumans-van Diepen et al. 1995). Its composition, however, appears not to be suitable for cultivating the fishinfecting $T$. borreli. We observed that trypanoplasms incubated in RPMI 1640 died significantly earlier compared to cultures in L15, HBSS, or MEM-medium. A successful cultivation of the flagellate was possible in a mixture of MEM, L15 and HBSS. This medium closely resembles the TDL medium used by Wang \& Belosevic (1994) for cultivation of Trypansoma danilewskyi from the blood of goldfish Carassius auratus and by Li \& Woo (1996) for the cultivation of Trypanoplasma catostomi from the blood of white sucker Catostomus commersoni. Flagellates cultivated in these media remained infective for their piscine hosts (Wang \& Belosevic 1994, Li \& Woo 1996, present study).

Trypanoplasma salmositica, a species closely related to $T$. borreli, multiplied rapidly in a modified MEM medium supplemented with $10 \%(\mathrm{~V} / \mathrm{v})$ heat-inactivated FBS (Woo \& Poynton 1995). In the present study $T$. borreli did not grow in

trypanoplasms propagated rapidly but lost their infectivity to fish. Fish trypanosomes (e.g. Trypanosoma carassii (syn. danilewskyi) transform to epimastigote stages when cultivated in SNB 9 media (Lom \& Dykova 1992) and lose their infectivity to fish. Unlike trypanosomes, trypanoplasms do not undergo morphological transformations from trypomastigote bloodstream stages to epimastigote stages during their cyclical development. In the digestive tract of the leech, $T$. borreli multiplies rapidly and produces numerous small and short flagellate cells which later elongate and form long and slender flagellates (Kruse et al. 1989). All stages from the leech however were found to be infective when inoculated into recipient fish (Kruse et al. 1989). When cultivated in SNB 9 or LIT medium, $T$. borreli transformed to small and short cells and lost its infectivity to carp (Peckova \& Lom 1990, Lom \& Dykova 1992). In our experiments, T. borreli did not undergo a morphological transformation during the in vitro cultivation and retained its infectivity to carp.

Attempts to maintain fish infective strains of Trypanoplasma borreli in the tissue culture media RPMI 1640 or L15 medium supplemented with FBS failed. Initially, the cell culture medium RPMI 1640 was chosen because it was strongly recommended by Hill \& Hirumi (1983) for the cultivation of animal infective strains of mammalian trypanosomes and was widely used for cultivating carp peripheral blood leukocytes media which contained no carp serum, but substantial multiplication of $T$. borreli was recorded when 5 to $10 \%$ heat-inactivated carp serum was added to the culture media. These findings correspond to observations of Trypanosoma danilewskyi, which also required the addition of fish serum (goldfish, carp or tin foil barb Puntius schwanenfeldi; Bienek \& Belosevic 1997, Overath et al. 1998).

The culture system described in this study enables easy isolation and propagation of fish-infective strains of Trypanoplasma borreli which may be useful for cell biological or molecular genetic characterization of the parasite and studies on its interaction with the immune system of the fish.

Acknowledgements. Mr S. H. Leenstra and Dr G. Wiegertjes, Wageningen Agricultural University, The Netherlands, kindly provided fertilized carp eggs. We are grateful to Mr U. Rabe for assistance with FACS measurements. This study was financially supported by a DFG (Deutsche Forschungsgemeinschaft) grant to D.S. and J.S.

\section{LITERATURE CITED}

Bienek DR, Belosevic M (1997) Comparative assessment of growth of Tirypanosoma danilewskyi (Laveran \& Mesnil) in medium containing fish or mammalian serum. J Fish Dis 20:217-221

Bunnajirakul S, Steinhagen D, Hetzel U, Körting W, Drommer W (2000) A study of sequential histopathology of Trypanoplasma borreli (Protozoa: Kinetoplastida) in susceptible 
common carp Cyprinus carpio. Dis Aquat Org 39:221-229

Hajdu E, Matskasi I (1984) In vitro cultivation of Trypanoplasma strains isolated from pike and leech (preliminary report). Acta Vet Hung 32:79-81

Hill GC, Hirumi H (1983) African trypanosomes. In: Jensen JB (ed) In vitro cultivation of protozoan parasites. CRC Press, Boca Raton, FL, p 193-219

Jones SRM, Palmen M, van Muiswinkel WB (1993) The effects of inoculum route and dose on the immune response of common carp. Cyprinus carpio to the blood parasite, Trypanoplasma borreli. Vet Immunol Immunopathol 36:369-378

Jones SRM, Wiegertjes GF, van Muiswinkel WB (1995) Modulation of carp (Cyprinus carpio L.) cellular immune function in vitro caused by the blood parasite, Trypanoplasma borreli Laveran \& Mesnil. Fish Shellfish Immunol 5: $381-383$

Koumans-van Diepen JCE (1993) Characterisation of fish leucocytes. An immunocytochemical and functional study in carp (Cyprinus carpio L.). PhD thesis, Wageningen Agricultural University, Wageningen

Kruse P, Steinhagen D, Körting W (1989) Development of Trypanoplasma borreli (Mastigophora: Kinetoplastida) in the leech vector Piscicola geometra and its infectivity for the common carp, Cyprinus carpio. J Parasitol 75:527-530

Li S, Woo PTK (1996) Effects of temperature and white sucker [Catostomus commersoni] serum supplement on the in vitro multiplication of Cryptobia catostomi in cell-free medium. Parasitol Res 82:276-278

Lom J, Dykova I (1992) Protozoan parasites of fishes. Developments in Aquaculture and Fisheries Science, 26. Elsevier, Amsterdam

Nohynkova E (1984) In vitro cultivation of the bodonid flagellate Trypanoplasma borreli. J Protozool 32:52 (Abstract)

Opperdoes FR, Nohynkova E, van Schaftingen E, Lambeir AM, Veenhuis M, van Roy J (1988) Demonstration of glycosomes (microbodies) in the bodonid flagellates Trypanoplasma borreli (Protozoa: Kinetoplastida). Mol Biochem Parasitol 30:155-164

Overath P, Ruoff J, Stierhof YP, Haag J, Tichy H, Dykova I,

Editorial responsibility: Otto Kinne (Managing Editor), Oldendorf/Luhe, Germany
Lom J (1998) Cultivation of blood stream forms of Trypanosoma carassii, a common parasite of freshwater fish Parasitol Res 84:343-347

Pechold K, Kabelitz D (1998) Measurement of cellular proliferation. In: Kaufmann SHE, Kabelitz D (eds) Immunoloy of infection. Methods in microbiology, Vol 25. Academic Press, San Diego, p 59-78

Peckova H, Lom J (1990) Growth, morphology and division of flagellates of the genus Trypanoplasma (Protozoa, Kinetoplastida) in vitro. Parasitol Res 76:553-558

Schuberth HJ, Anders I, Pape U, Leibold W (1992) Onedimensional isoelectric focusing and immunoblotting of equine MHC class I molecules. Anim Genet 23:87-95

Steinhagen D, Kruse P, Körting W (1989) The parasitemia of cloned Trypanoplasma borreli Laveran and Mesnil, 1901, in laboratory-infected common carp (Cyprinus carpio L.) J Parasitol 75:685-689

Trotter J (1998) WinMDI 2.7 software package. http://www facs.scripps.edu/software.html

Wang R, Belosevic M (1994) Cultivation of Trypanosoma danilewskyi (Laveran \& Mesnil, 1904) in serum-free medium and assessment of the course of infection in goldfish, Carassius auratus (L.). J Fish Dis 17:47-56

Wiegertjes GF, Groeneveld A, van Muiswinkel WB (1995) Genetic variation in susceptibility to Trypanoplasma borreli infection in common carp (Cyprinus carpio L.). Vet Immunol Immunopathol 47:153-161

Wiemer EAC, Hannaert V, an den Ijssel PRLA, van Roy J, Opperdoes FR, Michels PAM (1995) Molecular analysis of glyceraldehyde-3-phosphate dehydrogenase in Trypanoplasma borrell; an evolutionary scenario of subcellular compartment in kinetoplastida. J Mol Evol 40:443-454

Woo PTK, Li S (1990) In vitro attenuation of Cryptobia salmositica and its use as a live vaccine against cryptobiosis in Oncorhynchus mykiss. J Parasitol 76:752-755

Woo PTK, Poynton SL (1995) Diplomonodida, Kinetoplastida and Amoebida (Phylum Sarcomastigophora). In: Woo PTK (ed) Fish diseases and disorders, Vol 1. Protozoan and metazoan infections. CAB International, Wallingford, p $27-96$

Submitted: January 25, 2000; Accepted: May 4, 2000 Proofs received from author(s): June 19, 2000 